\title{
INTERAÇÃO INSETO PLANTA: colonização vegetal no entorno de termiteiros de Syntermitinae (Blattodea)
}

Luiz Roberto OLVEIRA ${ }^{1}$

Edimar Agnaldo MOREIRA ${ }^{2}$

${ }^{1}$ Graduando em licenciatura em Ciências Biológicas, Faculdade de Ciências e Tecnologias de Campos Gerais FACICAMG. luizrobertooliveira@hotmail.com

${ }^{2}$ Professor Mestre, docente da Faculdade de Ciências e Tecnologias de Campos Gerais FACICA-MG. edimarbio@hotmail.com.

Recebido em: 12/01/2016 - Aprovado em: 13/08/2016 - Disponibilizado em: 18/12/2016

\section{RESUMO:}

O estudo buscou determinar se fatores como proximidade do termiteiro e o sistema de manejo são capazes de influenciar na colonização vegetal de cupinzeiros construídos por espécies de da Subfamília Syntermitinae. Os cupins são organismos extremamente importantes nos ecossistemas, principalmente nos trópicos, tem grande papel na ciclagem de nutrientes e na formação do solo, modificam a estrutura do habitat influenciando nas espécies de plantas e animais. Os termiteiros possuem uma alta taxa de nitrogênio e maior concentração de carbono e outros nutrientes, que pelo processo de erosão são levados para o solo no entorno do termiteiro causando alterações na estrutura e fertilidade do solo. Os dados foram coletados em duas pastagens nos municípios de Campo do Meio e Campos Gerais onde foi coletado um total de 205 amostras. A influência na vegetação foi analisada de acordo com o raio da distância do termiteiro sendo de 0 a $1 \mathrm{~m}$ e 1 a $2 \mathrm{~m}$. Pode-se observar que pastagens ativas na criação de gado podem induzir respostas diferentes de pastagens convencionais, além disso, a ação dos cupins é capaz aumentar a riqueza absoluta de morfotipos vegetais próxima ao ninho da colônia.

Palavras-chave: Complexidade vegetal. Cupins. Qualidade do Solo.

\section{INSECT PLANT INTERACTIONS: vegetable colonization any surrounding termites of Syntermitinae (Blattodea )}

\begin{abstract}
:
The study sought to determine whether factors such as proximity to the termite colony and the management system are able to influence the plant colonization of termite mounds built by species of the subfamily Syntermitinae. Termites are extremely important organisms in ecosystems, especially in the tropics, has great role in nutrient cycling and soil formation, modify the habitat structure influencing the species of plants and animals. The termites have a high rate of nitrogen and highest concentration of $\mathrm{C}$ and other nutrients, which the erosion process are taken to the soil surrounding the termite colony causing changes in the structure and soil fertility. Data were collected in two grasslands in Campo do Meio and Campos Gerais of municipalities where it collected samples from 107 termites and second pasture in the municipality of Campos Gerais where he collected 98 samples, the impact on vegetation will be analyzed according to the radius of the distance from the termite colony It is from 0 to $1 \mathrm{~m}$ and 1 to $2 \mathrm{~m}$. Overall we can see that active pastures in livestock can induce different responses of conventional pastures also the action of termites, especially in its activities performed are able to increase the absolute wealth of vegetables morphotypes next to the nest of the colony.

Keywords: Vegetable complexity. Termites. Soil Quality.
\end{abstract}

\section{INTRODUÇÃO}

Os insetos possuem uma importância relevante nos processos biológicos em ecossistemas naturais (WINK et al., 2005), atuando também como bioindicadores da degradação ambiental, dentre estes insetos de, destacamos a ordem Blattodea, mais especificamente a Superfamília Termitoidea, que inclui os cupins, comumente conhecido como os siriris, aleluias, térmitas. Estes insetos têm sido amplamente estudados, pois os produtores são 
diretamente afetados por suas ações no ecossistema (LIMA; COSTA-LEORNARDO, 2007). Os cupins são estudados freqüentemente no Brasil onde ocorre a presença de quatro famílias: Kalotermitidae, Serritermitidae, Rhinotermitidae e Termitidae.

A subfamília Syntermitina é composta por cupins que apresentam como morfologia uma mandíbula bem desenvolvida e uma estrutura cefálica denominada nasus, que corresponde a uma projeção cefálica capaz de abrigar a glândula frontal responsável pela produção de compostos utilizados na defesa química do grupo. Algumas espécies são consideradas praga atualmente, pois danificam as raízes e também promovem a morte de mudas, além da extensão ocupada por seus ninhos em pastagens (CZEPAK; DE ARAÚJO; FERNANDES, 2007), podendo ataca culturas como cana-de-açúcar, arroz, amendoim, trigo e milho (LIMA; COSTA-LEORNARDO, 2007), e o número de indivíduos pode variar de acordo com a idade do ninho e características do local.

$\mathrm{Na}$ interação entre os seres com o meio ambiente em que vivem, há sempre a busca de uma homeostase, de forma a promover assim uma relação de troca de energia através das cadeias tróficas, acarretando em um fluxo de energia entre os níveis da cadeia (LOVATTO; SCHIEDECK; GARCIA, 2012). Esta relação também está presente entre insetos e plantas, ocorrendo a cerca de 300 milhões de anos, e essas relações ecológicas podem ser tanto positivas quanto negativas (DÁTTILO etal., 2009).

Os cupins são de extrema importância para o solo, pois sua capacidade de construir ninhos promove a concentração de nutrientes no solo, aumentando o processo de ciclagem de nutrientes (ANDERSON, 2005), (COSTALEONARDO; REBELO, 2002),(SILVA; MENDONÇA, 2007), contribuindo assim para a ciclagem de nutrientes no entorno do ninho.

O estudo buscou determinar se fatores como proximidade do termiteiro e sistemas de manejo são capazes de influenciar na colonização vegetal no entorno de cupinzeiros construídos por espécies da Subfamília Syntermitinae.

\section{MATERIAL E MÉTODOS}

O estudo foi realizado no mês de agosto de 2015 em uma área de pastagem no município de Campo do Meio e Campos Gerais, Minas Gerais, Brasil. O município de Campo do Meio fica localizado no sul de Minas Gerais, a cidade possui grande parte da sua extensão zonas rurais e com grande incidência de atividades agropecuárias, a cidade também possui uma Fauna e Flora muito rica e diversa. A cidade possui a altitude média de 780 metros acima de nível do mar e 1.083 metros em sua altitude máxima, a topografia da cidade é composta por $70 \%$ do relevo plano, $20 \%$ ondulado e $10 \%$ montanhoso.

O município de Campo do Meio, Minas Gerais, Brasil tem como solo predominante o tipo "Le- Latossolo Vermelho Escuro" com uma textura argilosa segundo o Instituto de Geociências Aplicadas (IGA-CETEC). O município possui grandes quantidades de pastos que são utilizados principalmente para a criação de bovinos, o a incidência de cupinzeiros nos pastos do município é grande, o que modifica o 
aspecto visual dos pastos e também a características do solo físicas do solo.

O município de Campos Gerais, Minas Gerais, Brasil, tem aproximadamente 28.783 habitantes, numero estimado em 2013. A principal fonte de rendo do município é a agropecuária, tem como solo predominante o tipo "Le- Latossolo Vermelho Escuro" segundo o IGA-CETEC. A presença de pasto neste município é comum sendo parte importante da paisagem local.

Como o trabalho buscou investigar eventos que ocorrem naturalmente no ambiente, a pesquisa assume caráter exploratório. Assim os dados trarão compreensão para o tema proposto.

Para a análise dos termiteiros, foram escolhidos 90 cupinzeiros (réplicas) para cada pastagem analisadas. As possíveis espécies Cornitermes cumulans, Procornitermes araujoi, Sulvestritermes euamignathus e Syntermes obtusos possuem hábitos de forrageamento e nidificação específicos, podendo influenciar diferentemente na composição do solo que circunda o ninho. Serão feitas amostragens de morfotipos vegetais encontradas ao redor do ninho. A figura 1 mostra duas áreas de coleta. A área $\mathrm{A}$ corresponde a um raio de $1 \mathrm{~m}$ do ninho amostrado, onde foram feitas coletas de morfotipos vegetais que podem estar sendo influenciados pela composição do ninho. A área B representa o ponto de amostragem em que a possível influência já não ocorra. Além da diversidade amostrada, foram analisados padrões de crescimento de morfotipos vegetais das duas áreas próximas aos termiteiros.
Figura 1: delineamento do método de amostragem

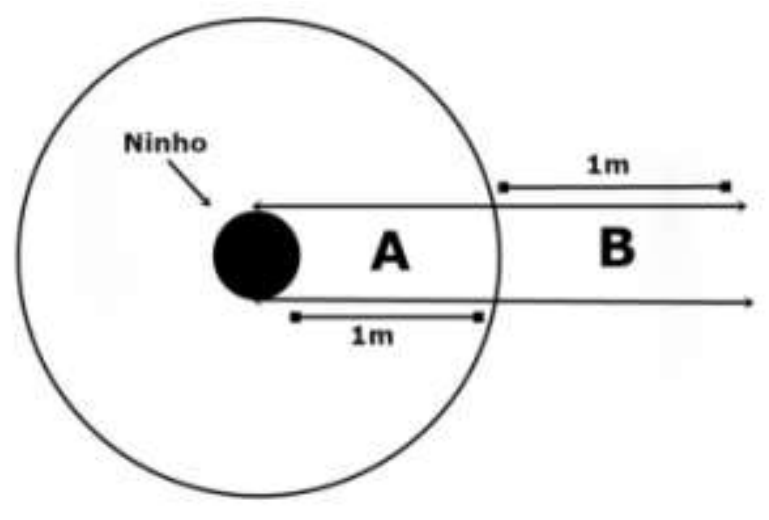

Fonte-Oliveira 2015

Para comparar as amostragens entre espécies foi utilizada a distribuição boxplot que permite visualização dos intervalos, bem como concentrações absolutas. Para verificar possíveis padrões de complexidade vegetal entre espécies utilizamos teste Kruskal Wallis, com nível de significância de $95 \%$.

\section{RESULTADOS E DISCUSSÃO}

Ao amostrar as pastagens selecionadas nos municípios de Campos Gerais e Campo do Meio, foram inspecionados 98 e 107 termiteiros nas duas cidades respectivamente, como pode ser visto nos quadros 1 e 2 , as quais mostram a relação da riqueza de morfotipos vegetais no entorno de cada ninho/colônia.

Quando foi verificado se houver diferença entre as pastagens na análise da complexidade vegetal local, pode-se observar que na pastagem 2 (Campos Gerais) no raio de $1 \mathrm{~m}$ de entorno do ninho a riqueza de espécies foi maior que na pastagem 1 (Campo do Meio), visto que ao passar da pastagem 1 para a 2 houve um aumento de 7,79 
na riqueza absoluta (Kruskal-Wallis $\mathrm{p}<0,05)$, (Gráfico 1).

Gráfico 1. Diferenças observadas na riqueza de morfotipos vegetais no entorno de termiteiros. P1: Pastagem 1; P2: Pastagem 2; 1m: Raio de um metro de entorno do ninho.

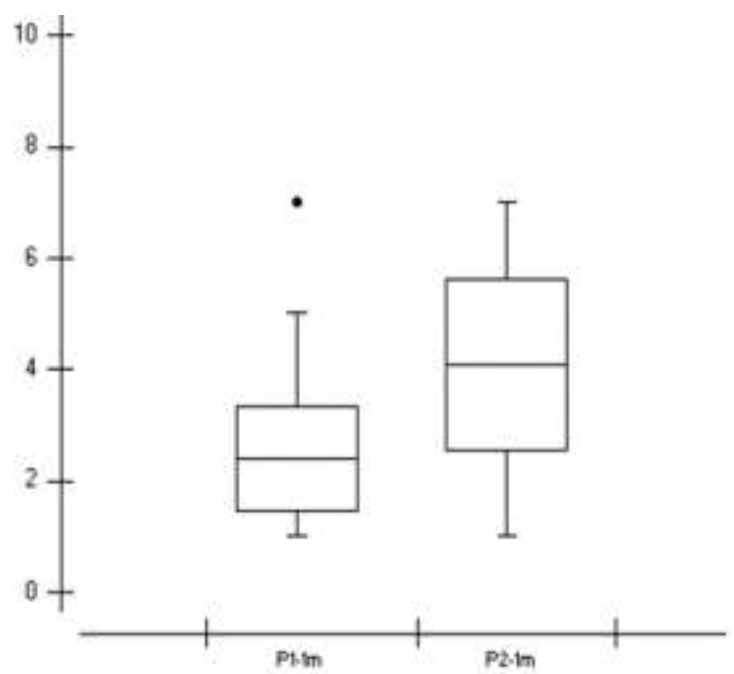

Fonte: OLIVEIRA (2015).

Ao analisar o mesmo quesito de pastagem, porém na distância de 2 metros de raio, observamos que o aumento permaneceu, porém com uma frequência menor. Ao passar da pastagem 1 para a 2 a riqueza absoluta de morfotipos aumentou em 2,05 (KruskalWallis p $<0,05)$. (Gráfico 2).

Gráfico 2. Diferenças observadas na riqueza de morfotipos vegetais no entorno de termiteiros. P1: Pastagem 1; P2: Pastagem 2; $2 \mathrm{~m}$ : Raio de dois metros de entorno do ninho.

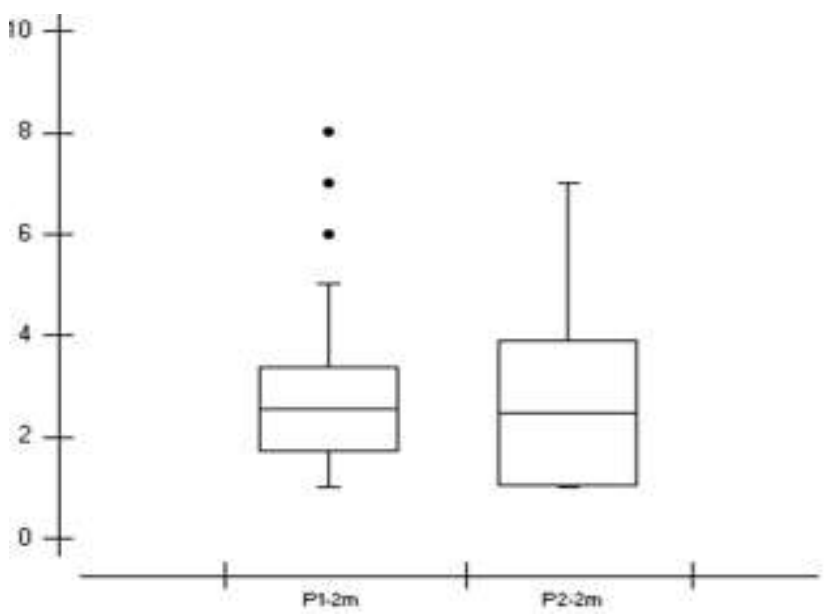

Fonte: OLIVEIRA (2015).

Também foi avaliada a riqueza absoluta de acordo com a proximidade do ninho observado, desta forma, na pastagem 1, verificou-se um padrão não esperado, quando aumentou a distância de amostragem dos morfotipos do termiteiro, a riqueza absoluta aumentou em 3,72 indivíduos (Kruskal-Wallis $\mathrm{p}=0,05)$, como pode ser observado no Gráfico 3. (Gráfico 3).

Gráfico 3. Diferenças observadas na riqueza de morfotipos vegetais no entorno de termiteiros. P1: Pastagem 1; 1m: Raio de um metro de entorno do ninho. 2; 2m: Raio de dois metros de entorno do ninho.

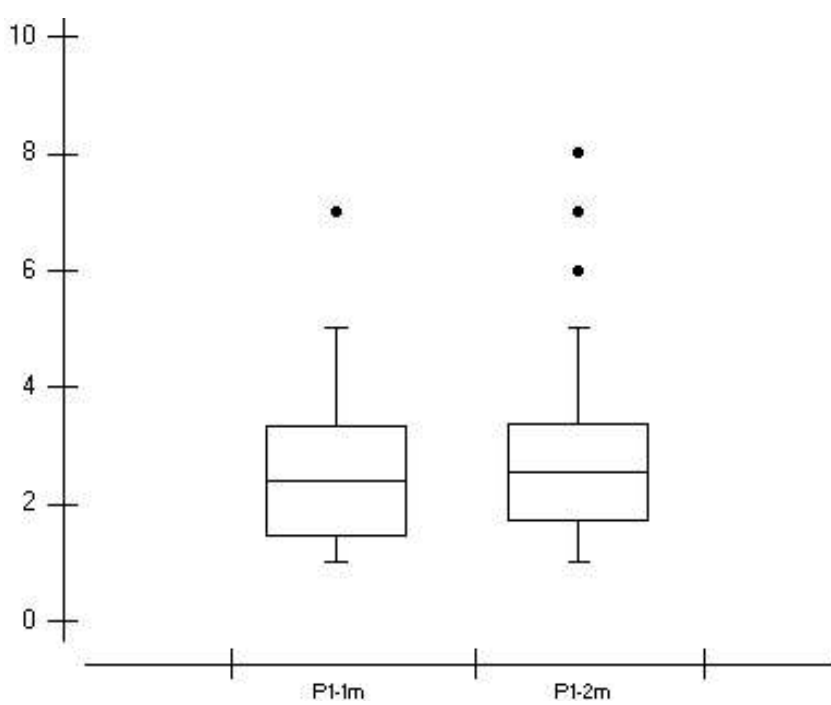

Fonte: OLIVEIRA (2015). 
Ao se avaliar a pastagem 2 o oposto ocorreu, ao passar do raio de um metro para 2 a riqueza absoluta diminuiu em 6,88 (Kruskal-Wallis $\mathrm{p}=0,05$ ), como visto no gráfico 4. (Gráfico 4).

Gráfico 4. Diferenças observadas na riqueza de morfotipos vegetais no entorno de termiteiros. P2: Pastagem 2; 1m: Raio de um metro de entorno do ninho. 2; $2 \mathrm{~m}$ : Raio de dois metros de entorno do ninho.

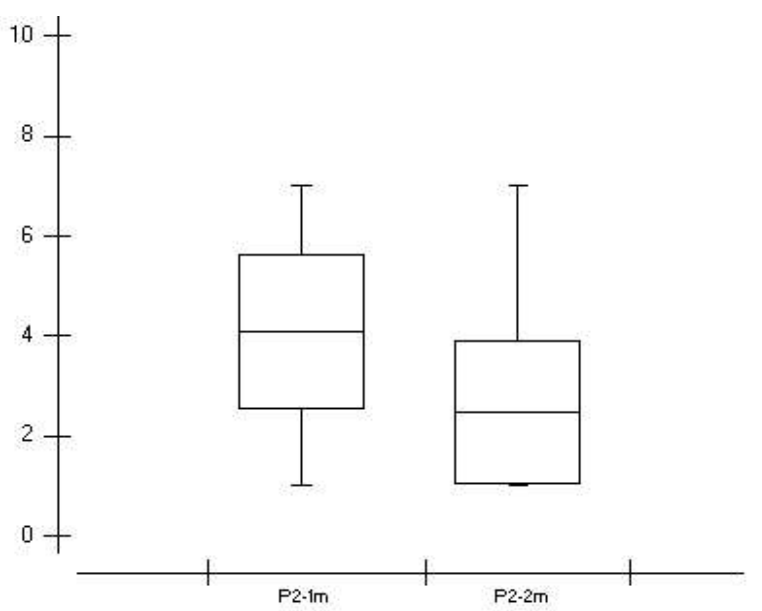

Fonte: OLIVEIRA (2015).

Averiguou-se na pastagem 1 , que a criação de gado está ativa, assim a deposição de massas fecais no solo é contínua na região. A pastagem de Campos Gerais possui presença de gado em épocas alternadas, sendo que na ocasião da coleta a pastagem não estava sendo ocupada pelo rebanho, nem mesmo foram observadas massas fecais depositadas.

$\mathrm{Na}$ pastagem 1 ocorreu algo inesperado, em que quanto mais longe do ninho (2m) maior foi a diversidade, isso pode estar relacionado pela pastagem estar ativa atualmente, a maior deposição de massas fecais garante um reabastecimento de matéria orgânica no solo, possibilitando a ocupação por espécies vegetais, como observado nos estudos de Van Den Berg (1995) e Alvarenga (1996). Os autores demonstram que sistemas de uso do solo diferentes são capazes de proporcionar condições específicas para ocupação das populações.

Já é observado que a fragmentação de áreas naturais bem como a formação de matrizes pode alterar a composição das comunidades associadas ou dependentes do solo. O motivo disto é devido a alteração da quantidade e qualidade da serapilheira bem como a alteração da composição da flora (RANTALAINEN et al., 2004). Observando a paisagem como um todo, a variação de tipos de vegetação ou estágios sucessionais também tem efeitos sobre o padrão de diversidade e composição da comunidade edáfica (CHUST et al., 2003).

Como na pastagem 1 a presença de massas fecais era constante, a utilização desse recurso pelos cupins, bem como sua incorporação no ninho e próximo a ele, pode ser complicada, visto que esses insetos coexistem com besouros escarabeíneos explorando o mesmo recurso (fezes). Assim a possibilidade de um maior grau de recrutamento pelos besouros pode estar realizando a alocação de recurso em pastagens ativas (MOREIRA, ARAB, 2015 - no prelo). 
Quando observamos a pastagem de Campos Gerais, podemos notar que a medida que o raio se fechava próximo ao termiteiro, a riqueza absoluta dos morfotipos vegetais aumentava. Isso ocorreu devido a possibilidade da qualidade do solo, próxima ao cupinzeiro ser mais rica em nutrientes, devido hábito de acumular material vegetal dentro dos ninhos (CASTRO; JÚNIOR, 2002; SILVA; MENDONÇA, 2007; LEE; WOOD, 1971), e ao processo de biotubação do solo (SILVA; MENDONÇA, 2007). O acumulo de solo realizado pela atividade dos cupins variam de 0,05 a 0,4-1 $\mathrm{mm}$ por ano (LEE; WOOD, 1971). Em um intervalo de 1000 anos, $37 \mathrm{~cm}$ do subsolo podem ser realocados para a superfície pela bioturbação realizada pelos cupins Holt e Lepage (2000).

No experimento realizado por Ourives e Oliveira (2015) - no prelo, demonstrou que a utilização do substrato derivado do ninho de cupim de montículo, é capaz de aumentar o crescimento inicial de leguminosas, quando avaliado junto ao solo normal. A composição do solo que é alterada por estes insetos juntamente com as funções ecológicas desempenhadas por estes, garante uma melhor condição para a colonização por plantas.

Tratando-se de funções ecológicas a aeração do solo também pode ser uma atividade desempenhada pelos cupins, devido a formação de túneis podendo atingir grandes profundidades aumentando a porosidade do solo e melhorando a umidade local pelo favorecimento da infiltração e retenção de agua promovida pelas extensas galerias feitas por estes insetos (CONSTANTINO, 1999).

Com túneis transpassando grandes extensões de solo essa porosidade formada, também pode ser eficiente na infiltração e retenção de água, garantindo a umidade do local (PINHEIRO, 2013), o que é muito útil em pastagens que são constantemente compactadas pelo pisoteio do gado.

\section{CONCLUSÃO}

Conclui-se que a maior riqueza de vegetação, tanto a $1 \mathrm{~m}$ quanto $2 \mathrm{~m}$ de raio próximo aos ninhos ocorreu na pastagem em campos gerais. Em Campo do Meio (Pastagem 1) houve um aumento na riqueza absoluta de acordo com o aumento do raio (1 p/ 2m) e em Campos Gerais (Pastagem 2) houve decréscimo.

Pode-se inferir hipóteses quanto aos motivos desta diferença da riqueza, como o aumento da adubação realizado pelo gado e também outros fatores como competição por alimentos.

São necessários ainda, estudos que mostrem quais outros padrões podem estar envolvidos nas dinâmicas de colonização, assim trabalhos como este, podem ser utilizados na elaboração de planos de conservação da fauna desses insetos que atuam intensamente nos ecossistemas. 


\section{REFERÊNCIAS}

ALVARENGA, M. I. N. Propriedades físicas, químicas e biológicas de um Latossolo Vermelho-Escuro em diferentes ecossistemas. Lavras, Universidade Federal de Lavras, (Tese de Doutorado) 1996. 211p.

ANDERSON, M. Australian termites and nutrient recycling.Iowa: BIOL, 2005. 394p.

CASTRO JÚNIOR, P.R. Dinâmica da água em campos de Murundus do planalto dos Parecis. Tese (Doutorado em Geografia Física) - Programa de Pós-graduação em Geografia, Universidade de São Paulo, SP. 2002. $193 f$.

CONSTANTINO, R. Chave ilustrada para identificação dos gêneros de cupins (Insecta: Isoptera) que ocorrem no Brasil. Papéis avulsos de Zoologia, v.40, p.387-448, 1999.

COSTA-LEONARDO, A. M.; REBÊLO, J. M.

M. Cupins-praga: morfologia, biologia e controle. In: Cupins-praga: morfologia, biologia e controle. AMCL, 2002.

CZEPAK, C.; DE ARAÚJO, E. A.; FERNANDES, P. M. Ocorrência de espécies de cupins de montículo em pastagens no Estado de Goiás. Pesquisa Agropecuária Tropical (AgriculturalResearch in theTropics), v. 33, n. 1, p. 35-38, 2007.

DÁTTILO, W. et al. Interações mutualísticas entre formigas e plantas. EntomoBrasilis, v. 2, n. 2, p. 32-36, 2009.

HOLT, J.A.; LEPAGE, M. Termites and soil properties. In: ABE, T. et al. (Ed.). Termites, evolution, sociality, symbiosis, ecology.

Dordrecht: Kluwer Academic, p.389-407. 2000.

LEE, K.E.; WOOD, T.G. Physical and chemical effects on soils of some Australian termites, and their pedological significance.Pedobiologia, v.11, p.376-409, 1971.
LIMA, J. T.; COSTA-LEONARDO, A. M.. Recursos alimentares explorados pelos cupins (Insecta: Isoptera). Biota Neotropica, v. 7, n. 2, p. 243-250, 2007.

LOVATTO, Patrícia Braga; SCHIEDECK, Gustavo; GARCIA, Flávio Roberto Mello. A interação co-evolutiva entre insetos e plantas como estratégia ao manejo agroecológico em agroecossistemas sustentáveis. Interciencia, v. 37, n. 9, p. 657-663, 2012.

PINHEIRO, L. B. A. et al. Atributos edáficos e de termiteiros de cupim-de-montículo (Isoptera: Termitidae) em Pinheiral-RJ.Floresta

Ambient., Seropédica, v. 20, n. 4, p. 510520, Dec. 2013.

RANTALAINEN, M.L.; KONTIOLA, L.; HAIMI, J.; FRITZE, H.; SETÄLA, H. Influence of resource quality on the composition of soil decomposer community in fragmented and continuous habitat. Soil Biol. Biochem., 36:1983-1996, 2004.

SILVA, I.R; MENDONÇA, E. S. Matéria orgânica do solo. In: NOVAIS, R.F. et al. (Ed.). Fertilidade do solo. Viçosa: SBCS, 2007. p.275374.

SILVA, I.R; MENDONÇA, E. S. Matéria orgânica do solo. In: NOVAIS, R.F. et al. (Ed.). Fertilidade do solo. Viçosa: SBCS, 2007. p.275374.

vanden BERG, E. Estudo florístico e fitossociológico de uma floresta ripária em Itutinga, MG, e análise das correlações entre variáveis ambientais e a distribuição das espécies de porte arbóreo-arbustivo. Lavras, Universidade Federal de Lavras, 1995. 73p. (Tese de Mestrado).

WINK, C. et al. Insetos edáficos como indicadores da qualidade ambiental. Revista de CiênciasAgroveterinárias, v. 4, n. 1, p. 60-71, 2005. 